\title{
Tumores benignos de la mucosa oral
}

\section{Benign tumors in oral cavity}

\author{
Pérez-Salcedo L*, Bascones Martínez A**
}

\section{RESUMEN}

La mayoría de los tumores de los tejidos blandos pueden presentarse en varios sitios del organismo, así como en la mucosa bucal. En este artículo se van a describir los diferentes tipos de tumores benignos de la mucosa oral, se clasificarán según el tejido de procedencia. El diagnóstico definitivo será histológico y permitirá tomar una decisión terapéutica.

Palabras clave: Tumor benign, escisión quirúrgica.

\section{SUMMARY}

The majority of soft tissues tumors can be present in various sites of the organism, as well as in the oral cavity. In this paper, we will describe all the different types of benign tumors in the oral cavity, the classification will be according to the tissue of origin. The definitive diagnosis would be histological and this would provide the correct treatment.

Key words: Benign tumor, surgical excision.

Fecha de recepción: 17 de septiembre de 2008.

Aceptado para publicación: 1 de octubre de 2008.

* Máster de Periodoncia e Implantología. UCM.

** Catedrático de Medicina Oral y Periodoncia e Implantes. UCM.

Pérez-Salcedo L, Bascones Martínez A. Tumores benignos de la mucosa oral. Av. Odontoestomatol 2010; 26 (1): 11-18.

\section{INTRODUCCIÓN}

Se trata de una serie de entidades que se caracterizan por un crecimiento anormal en la boca o lengua con poca probabilidad de extenderse a otras partes del cuerpo. Los tumores benignos de la boca o lengua generalmente se presentan solos y crecen muy lentamente durante un periodo de 2 a 6 años. Pueden aparecer en los labios, encías, paladar, suelo de la boca o lengua (1).

Los signos y síntomas más frecuentes son:
- Un bulto en cualquier parte de la boca o lengua.

- Puede ulcerarse y sangrar.

- Puede interferir con la adhesión adecuada de las dentaduras postizas.

El diagnóstico de una entidad anormal en la cavidad oral es lo más importante y se debe identificar su naturaleza benigna o maligna, ayudados por una correcta historia y exploración clínica, aunque el diagnóstico definitivo que nos permitirá valorar el pronóstico y llevar a cabo una terapéutica adecuada, será la biopsia y el estudio histopatológico (Tabla 1). 


\begin{tabular}{|l|l|l|}
\hline \multicolumn{3}{|c|}{ TABLA 1 } \\
\hline & Tumor benigno & Tumor maligno \\
\hline Estructura & $\begin{array}{l}\text { Similar al tejido } \\
\text { de origen }\end{array}$ & Presenta atipias \\
\hline Crecimiento & Encapsulado & $\begin{array}{l}\text { Infiltrativo, } \\
\text { metástasis }\end{array}$ \\
\hline $\begin{array}{l}\text { Grado de } \\
\text { crecimiento }\end{array}$ & Lento & $\begin{array}{l}\text { Rápido y alto } \\
\text { índice mitótico }\end{array}$ \\
\hline
\end{tabular}

\section{CLASIFICACIÓN DE LOS TUMORES BENIGNOS DE LA MUCOSA ORAL}

La clasificación se basa en criterios histológicos dependiendo de la procedencia del tejido en el que se observa un crecimiento anormal (2).

La cavidad oral está tapizada por la mucosa oral, una estructura epitelio-conectiva que la recubre de forma completa. Los tumores que derivan de esta estructura pueden originarse tanto del epitelio estratificado escamoso como del corion subyacente. Por lo tanto, los apartados que se van a seguir en este artículo son:

1. Tumores de estirpe epitelial.

2. Tumores de estirpe conectiva.

3. Tumores de estirpe muscular.

4. Tumores vasculares.

5. Tumores melánicos.

6. Tumores nerviosos.

\section{TUMORES DE ESTIRPE EPITELIAL}

Dentro de este apartado vamos a describir el queratoacantoma, papiloma, verruga vulgar, condiloma acuminado y molluscum contagioso.

\section{Queratoacantoma}

El queratoacantoma es una neoplasia epitelial benigna, aun cuando algunas veces presenta muestras de crecimiento invasivo. El tumor de células espinosas empieza en la forma de un pequeño nódulo semiesférico, se desarrolla bastante rápido formando un abultamiento central y al cabo de un mes o a los dos meses alcanza su tamaño completo, que puede sobrepasar varios centímetros. En casos típicos existe un cráter central relleno de masa córnea cercado por un borde indurado e hinchado.

Aparece especialmente en la piel expuesta al sol y con menos frecuencia en la unión mucocutánea.

Es más frecuente en varones que en mujeres y preferentemente entre los 50-70 años de edad.

Se debe realizar el diagnóstico diferencial con el carcinoma de células espinosas.

La evolución es favorable ya que se suele producir la recurrencia espontánea. Aunque se suele eliminar quirúrgicamente para confirmar su diagnóstico de manera histológica $(3,4)$.

\section{Papiloma}

Es el tumor epitelial benigno más frecuente de la mucosa oral. Puede aparecer a cualquier edad sin diferencia entre sexos.

Los papilomas escamosos se manifiestan como lesiones de superficie rugosa, parecidas a una coliflor, cuyo tamaño no suele superar un centímetro. Su color oscila de blanco a gris. Ocasionalmente se pueden observar papilomas múltiples agrupados. Las localizaciones preferidas son la lengua y el paladar, menos habituales son la mucosa de la mejilla, la encía y los labios. Pero también pueden aparecer en cualquier otra localización.

En el diagnóstico diferencial se debe tener en cuenta, sobre todo en los papilomas de gran tamaño y superficie en forma de coliflor, preferentemente un carcinoma verrucoso inicial, además de las verrugas, el condiloma acuminado y las hiperplasias epiteliales focales.

Debido a una cierta tendencia a recidivas, se aconseja la escisión en sano (Figs. 1 y 2). 

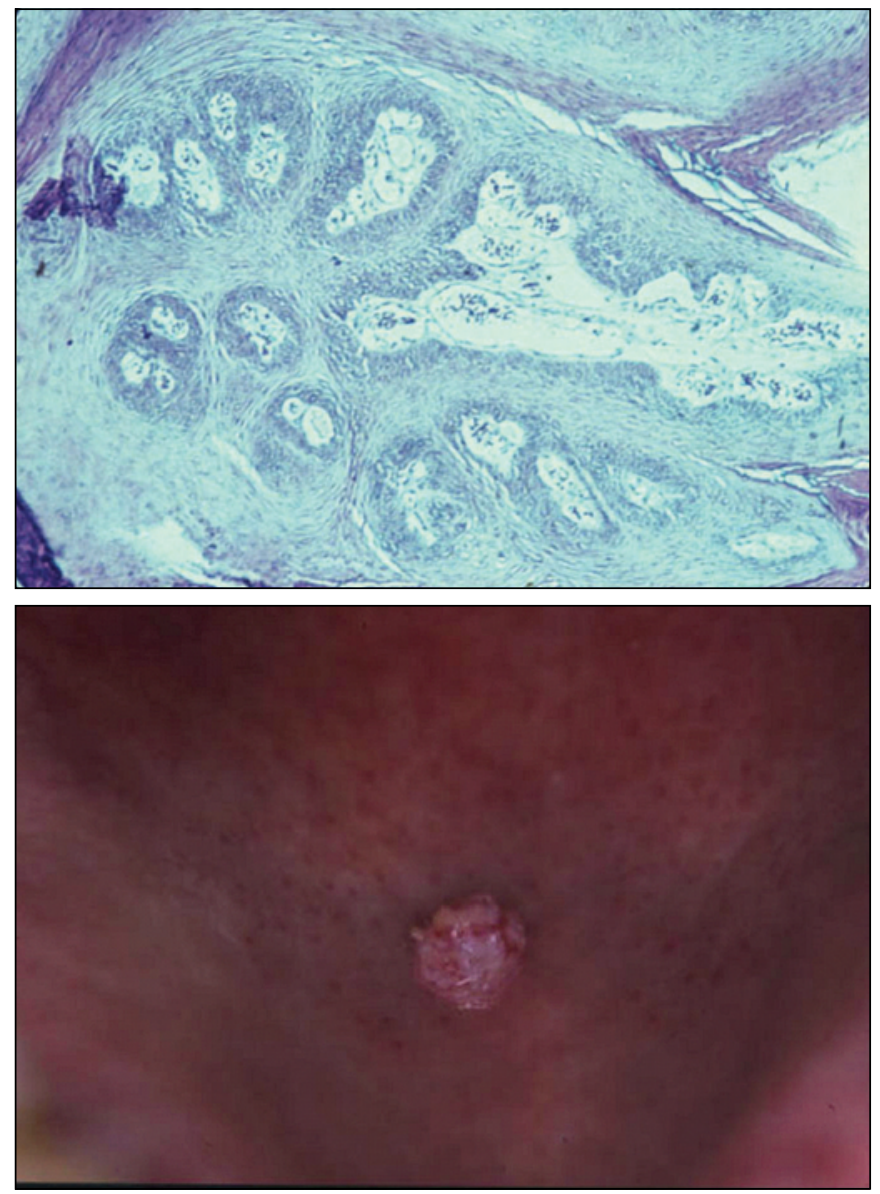

Figs. 1 y 2. Papilomas.

\section{Verruga vulgar}

Las verrugas vulgares se cuentan entre las alteraciones más frecuentes de la piel. Estas verrugas, generalmente inducidas por los virus del papiloma humanos tipo 1, 2 y 4, aparecen en niños (a menudo en edades escolares), jóvenes y adultos y se hallan preferentemente en las manos y dedos. Pueden aparecer de forma solitaria o múltiple, igualmente en cara como en cualquier parte de la piel. Hallazgos no tan inusuales se originan también en los labios y en la mucosa oral, donde van a parar probablemente a través del contacto con las verrugas de las manos. Las verrugas orales tienen un color más blanquecino y una estructura vellosa, de manera que no se diferencian clínicamente de los papilomas.

Las verrugas pueden perdurar durante años, no obstante pueden involucionar espontáneamente tras corto tiempo. Se observan más frecuentemente en enfermos con inmunidad celular significativamente disminuida que en otros grupos de población (5).

\section{Condiloma acuminado}

Está inducido por los virus del papiloma humanos tipo 6, 11 y 42 y se contagia por contacto orogenital (5).

Aparece inicialmente como una agrupación de nódulos simples, de color rosado que posteriormente crecen, desarrollan una masa papilar exofítica, blanda, pedunculada o sésil.

El tratamiento consiste en la extirpación de la lesión bien mediante cirugía, electrocirugía, electrodesecación o laserterapia. Sin embargo las recidivas son frecuentes como consecuencia de la naturaleza infecciosa de la lesión ya que se ha comprobado que los tejidos adyacentes de apariencia normal pueden albergar el virus y ser la fuente de las recurrencias (6) (Fig. 3).

\section{Molluscum contagioso}

La localización oral del Molluscum contagioso es poco frecuente, siendo la afectación cutánea la más habitual.

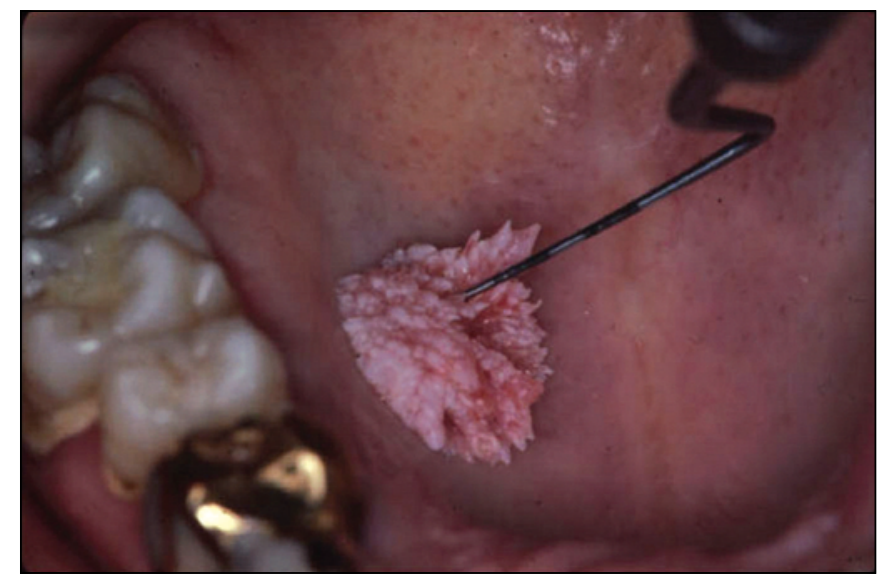

Fig. 3. Condiloma acuminado. 
Es una infección viral que se contagia de contacto piel-piel o por autoinoculación. Se suele observar en niños.

El tratamiento puede consistir en vigilar porque es autolimitada e involuciona espontáneamente o para evitar su extensión y contagio extirparlo bien mediante crioterapia, cirugía o bien por imiquimod tópico (7).

\section{TUMORES DE ESTIRPE CONECTIVA}

Las diferentes variedades de tejido conectivo pueden originar neoplasias benignas bucales. En este apartado se describirá: el lipoma, fibroma, mixoma, xantoma verruciforme, fascitis nodular.

\section{Lipoma}

Los lipomas, son raros en la cavidad oral en comparación con otras partes corporales, se hacen visibles clínicamente después de los 40 años. Estas formaciones submucosas que abomban la mucosa semiesféricamente se hallan preferentemente en la zona de la mejilla, de la lengua, del suelo de la boca, del paladar blando y de los labios; no obstante, pueden aparecer en cualquier parte en la que haya tejido seboso normalmente.

En situación superficial, el tumor benigno del tejido seboso trasluce amarillento a través de la mucosa generalmente inalterada. La consistencia de los lipomas orales, que por regla general aparecen aislados y están cercados por una cápsula de tejido conjuntivo, es blanda y puede simular una fluctuación al tacto. El tamaño a menudo tiene relación con la duración de la anamnesis y permite deducir la actitud del paciente.

El tratamiento de elección consiste en la extirpación quirúrgica (8).

\section{Fibroma}

Es una neoformación nodular, con diámetro medio aproximado de $1 \mathrm{~cm}$, constituida por una masa cen- tral fibroconectiva. Se encuentra bien circunscrito dispuesto sobre una base pedunculada.

Los fibromas crecen muy lentamente y generalmente interrumpen su crecimiento hasta alcanzar un tamaño determinado. Pueden tener desde una consistencia blanda hasta dura, que depende de la cantidad y disposición de las fibras de colágeno, así como de la participación de sustancias básicas líquidas.

Su localización habitual suele ser las mejillas, lengua, paladar y encía.

Se aconseja la extirpación de los fibromas, porque no siempre es suficiente el diagnóstico diferencial clínico para la exclusión de otros tumores sólidos (9) (Fig. 4).

\section{Mixoma}

El mixoma de los tejidos blandos orales es una lesión rara que se manifiesta como una masa submucosa de crecimiento lento sin características clínicas genuinas. Puede aparecer a cualquier edad, sin predilección por ningún sexo y en cualquier localización intraoral, aunque con cierta predilección por el paladar.

Estos tumores son localmente agresivos y tienen tendencia a recidivar, por lo que debe procurarse una escisión completa $(6,10)$.

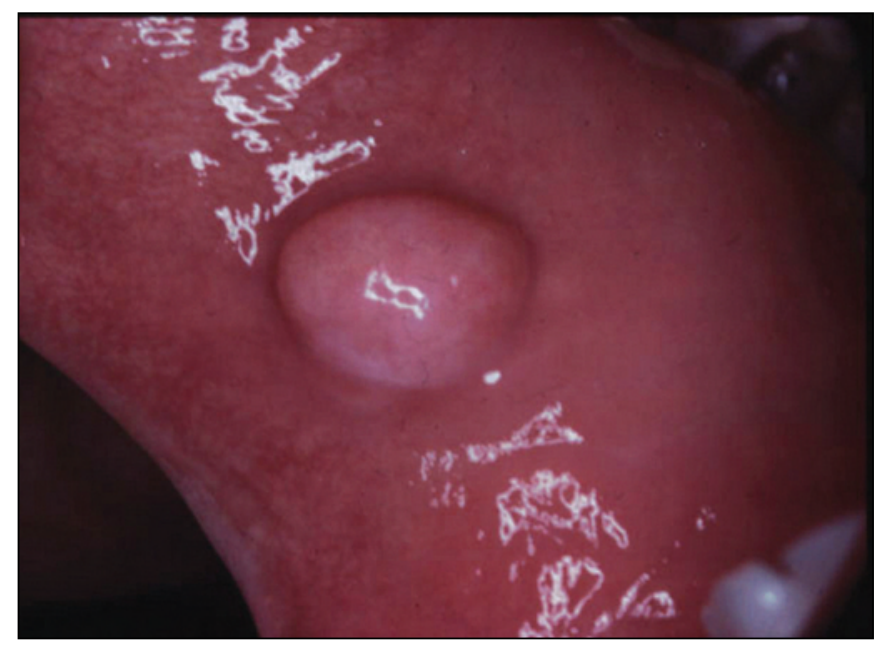

Fig. 4. Fibroma. 


\section{Xantoma verruciforme}

Es una lesión benigna de etiología desconocida que se suele localizar en las mucosas y piel. Está constituido por histiocitos espumosos con hiperplasia papilomatosa e hiperqueratosis en el epitelio suprayacente, lo cual le confiere un aspecto macroscópico semejante a la verruga vulgar.

Se debe realizar la extirpación quirúrgica (11).

\section{Fascitis nodular}

Es un crecimiento de tejido conectivo fibroso de etiología desconocida aunque probablemente de origen traumático. En un pequeño porcentaje se localiza en el área maxilofacial aunque en la mayoría de los casos aparecen en el tronco y las extremidades.

Presenta crecimiento rápido y sensibilidad e incluso dolor. Cursa como una masa firme y dura.

El diagnóstico diferencial debe establecerse fundamentalmente con lesiones fibrosas de tipo maligno que son más infiltrativas.

El tratamiento consiste en la cirugía conservadora ya que no suelen aparecer recidivas (12).

Por último, en este apartado de tumores de estirpe conectiva se debe hacer mención a los fibrolipomas que aunque aparecen de manera poco frecuente también pertenecen a este grupo de tumores benignos. Suelen aparecer más frecuentemente en varones (13).

Presentan una superficie brillante, rosada y lisa. El tratamiento debe ser la escisión quirúrgica (14).

\section{TUMORES DE ESTIRPE MUSCULAR}

Las neoplasias benignas originadas en el tejido muscular son raras en la cavidad bucal. En este apartado se describirán el leioma y el rabdomioma.

\section{Leioma}

Los leiomas son tumores benignos originados en el músculo liso. Su localización más frecuente es el útero, el tracto gastrointestinal y la piel. Se presenta habitualmente entre los 40 y 49 años de edad, siendo muy rara su aparición en la infancia y en la senectud. Son muy infrecuentes a nivel de la cavidad oral, pero cuando se dan en esa localización, asientan principalmente en la lengua, los labios o el paladar.

Inicialmente suelen presentarse como una masa muy bien definida, de lento crecimiento y totalmente asintomática. En raras ocasiones producen dolor. Su tratamiento es casi siempre quirúrgico, siendo las recurrencias excepcionales.

Dada su clínica inespecífica, su diagnóstico es principalmente histológico, observándose en las muestras una proliferación de células musculares lisas, sin focos de necrosis y con escasas mitosis (15).

\section{Rabdomioma}

Este tipo de tumores se suele presentar en la región dorsal de la lengua y están constituidos por células musculares estriadas. La estriación se puede observar con hematoxilina.

\section{TUMORES VASCULARES}

\section{Hemangioma}

Los hemangiomas suelen estar presentes en el momento del nacimiento o pueden aparecer en la infancia.

El aspecto clínico es una mácula rosada que al presionar sobre ella suele palidecer.

Suelen desaparecer espontáneamente por lo que se recomienda vigilarlo hasta que esto ocurra. Aunque otra opción terapéutica podría ser la extirpación quirúrgica o el tratamiento con láser de diodo que recientemente ha revelado buenos resultados (16).

\section{Linfangioma}

Los linfangiomas son masas hamartomatosas, frecuentes en la cavidad oral, constituidas por capilares 
que contienen la linfa. Dependiendo del tamaño se clasifican en una forma capilar y otra cavernosa.

También suele aparecer el periodo perinatal o en los primeros años de vida (17).

Es una lesión indolora y aparece en forma superficial como proyecciones papilares únicas o múltiples en la mucosa. Su color varía del gris al azul claro o rojo.

Se encuentra más frecuentemente en la lengua.

El diagnóstico diferencial debe incluir a los hemangiomas, los mucoceles y las lesiones vesiculares.

El tratamiento debe ser la espera a la involución espontánea, en caso de que no sea posible se debe realizar el tratamiento quirúrgico aunque con riesgo de hemorragias $(6,17)$.

\section{Hemangioendotelioma}

Los hemangioendoteliomas son un grupo heterogéneo de neoplasias vasculares con una alta tendencia a la recidiva aunque una rara predisposición a la metástasis.

Suele afectar más frecuentemente a adultos. Solo se ha descrito un caso en la cavidad oral hasta el momento.

El tratamiento debe ser la escisión quirúrgica con 1 $\mathrm{cm}$ de margen de seguridad (18).

\section{Hemangiopericitoma}

El hemangiopericitoma es un tumor vascular agresivo con alta propensión a la recurrencia y a la metástasis.

Suele aparecer en los tejidos blandos de las extremidades y el tronco, y es muy raro en la cavidad oral.

Se debe tratar con escisión quirúrgica con amplios márgenes de seguridad para evitar la recurrencia y la metástasis (19).

\section{Tumor glómico}

Esta neoplasia suele ser pequeña y con aspecto enquistado, es dolorosa y se halla sobre todo en la zona de las arterias finales de los dedos de las manos y pies. En la cavidad oral, el tumor glómico representa un hallazgo bastante raro (2).

\section{TUMORES MELÁNICOS}

\section{Nevus}

Nevus es una formación anómala de la piel o de la mucosa, circunscrita, benigna y la mayoría de las veces no hereditaria, que se genera por un trastorno en el desarrollo embrional. Los nevus pueden manifestarse en el nacimiento o bien aparecer en el curso de la vida.

Se clasifican en nevus pigmentario y nevus organoide.

\section{Nevus pigmentario}

Dentro de este tipo de nevus vamos a describir:

- Lentigo: Es una mancha por hiperpigmentación de la piel, bien delimitada y de color marrón oscuro, que se produce a causa de una acumulación de pigmento y un aumento de los melanocitos de la capa celular basal.

Puede aparecer por todo el cuerpo, sola, en grupos o difusa. Se presenta a cualquier edad. No muestra ninguna preferencia por las partes cutáneas con exposición solar, sino que se forma como pecas.

- Nevus nevocítico: se compone de nevocitos que no son propias de las partes integrantes de la piel. Las nevocélulas poseen igualmente la facultad de formar melanina, se disponen en la epidermis y se desarrollan probablemente a partir de melanocitos localizados en la epidermis.

Los nevus nevocíticos pueden ser congénitos o pueden aparecer en cualquier edad y crecer paulatinamente. Con la edad se suele producir una regresión. 


\section{Nevus organoide}

Según el tipo de tejido predominante en cada caso se puede distinguir nevus epitelial (por ejemplo nevus de las glándulas sebáceas), nevus del tejido conjuntivo y nevus vascular. Entre los nevus vasculares, los nevus flameus son los más frecuentes y los que adquieren mayor importancia de diagnóstico diferencial en la zona maxilofacial, porque pueden combinarse con otros trastornos no apreciables a simple vista (2).

\section{TUMORES NERVIOSOS}

El neurinoma es un tumor encapsulado que deriva de las células de Schwann. Es el tumor nervioso más frecuente en la cavidad oral, suele aparecer más frecuentemente en la lengua.

Suele aparecer en la segunda o tercera década de la vida, con predilección hacia las mujeres.

Clínicamente se presentan como un nódulo circunscrito que raramente es multinodular.

El tratamiento es la escisión quirúrgica (20).

\section{BIBLIOGRAFÍA}

1. Lindhe. Periodontología Clínica e Implantología Odontológica. $4^{a}$ Edición. Editorial Panamericana.

2. M. Strassburg/G. Knolle. Mucosa Oral. Atlas de enfermedades. Marban.

3. Feldman RJ, Maize JC. Multiple keratoacanthomas in a young woman. Int J Dermatol 2007;46(1):77-9.

4. Berrone S; De Gianni PP; Gallesio C. Keratoacanthoma of the lower lip. Minerva Stomatol 1992;41(12): 597-601.

5. Margotta V, Capogreco M. Soft tissue pathologies of the oral cavity. Minerva Stomatol 2003;52(1-2): 47-51.
6. Antonio Bascones Martínez. Medicina Bucal. Avances $3^{a}$ Edición Ariel.

7. Cutis. Treatment of molluscum contagiosum and herpes simplex virus cutaneous infections. 2007; 79(4 Suppl):11-7.

8. Brooks JK, Schaper MA, Schwartz KG, Nikitakis NG. Oral lipoma: report of three cases. Gent Dent 2008;56(2):172.

9. Shine $\mathrm{N}$, nor nurul Khasri $M$, Fitzgibbon J, O'Leary G. Solitary fibrous tumor of the floor of the mouth: case report and review of the literature. Ear Nose Throat J. 2006;85(7):4379.

10. Araki M, Kameoka S, Mastumoto N, Komiyama K. Usefulness of cone beam computed tomography for odontogenic myxoma. Dentomaxillofac Radiol 2007;36(7):423-7

11. Yu CH, Tsai TC, Wang JT, Liu BY, Wang YP, Sun A, Chiang CP. J Formos Med Assoc. Oral verruciform xanthoma: a clinicopathologic study of 15 cases. 2007;106(2):141-7.

12. Nair P, Barrett AW, Theodossy T. Br Oral nodular fasciitis: case report. J Oral Maxillofac Surg 2004; 42(4):360-2.

13. Scivetti M. Fibrolipoma gigante de la mejilla: a propósito de un caso. Av Odontoestomatol 2006; 22(1):33-6.

14. Janas A, Grzesiak-Janas G. The rare occurence of fibrolipomas. Otolaryngol Pol 2005;59(6): 895-8.

15. Luaces Rey, Lorenzo Franco, Gómez Oliveira, Patiño Seijas, Guitián, López-Cedrán Cembranos. Oral leiomyoma in retromolar trigone. A case report. Med Oral Patol Cir Bucal 2007;12 E53-5.

16. Francesca Angiero, Stefano Benedicenti, Georgios E. Romanos, Rolando Crippa. Photomedicine and Laser Surgery. April 1, 2008;26(2): $113-8$ 
17. Rodríguez Romero FJ. Linfangioma en labio inferior: una presentación inusual. Av Odontoestomatol 2008;24(3):208-10.

18. Fasolis M, Iaquinta C, Montesco MC, GarzinoDemo P, Tosco P, Tanteri G, Bonandini E, Ninfo $\mathrm{V}$, Berrone S. Composite hemangioendothelioma of the oral cavity: case report and review of the literature. Head Neck 2008;30(7): 974-9.

19. Ceylan A, Kagan Degerliyurt M, Celenk F, Ataç MS, Sabri Uslu S. Haemangiopericytoma of the hard palate. Dentomaxillofac Radiol. 2008;37(1): 58-61.

20. Ferreti Bonan PR, Martelli H Jr, Nogueira Dos Santos LA, Comini Mol V, Paes De Almeida O. Multinodular neurilemmoma of the tongue: a case report with differential immunohistochemical profile. Minerva Stomatol. 2008;57(1-2):71-5.

\section{CORRESPONDENCIA}

Leire Pérez-Salcedo

leireperezsalcedo@hotmail.com 